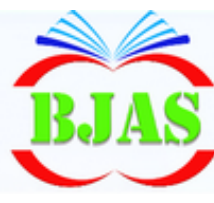

ISSN $1814-5868$
Available online at http://bajas.edu.iq

https://doi.org/10.37077/25200860.2021.34.1.03 College of Agriculture, University of Basrah

Basrah J. Agric. Sci., 34(1): 28-37, 2021

\section{Basrah Journal of Agricultural Sciences}

E-ISSN: 2520-0860

\title{
An assessment of Energy Consumption for Canola Production System in Iran (A Case Study: Amirkabir Agro-Industry)
}

\author{
Nasim Monjezi ${ }^{1 *} \&$ Esmaeil Hosseinzadeh ${ }^{2}$ \\ ${ }^{1}$ Department of Biosystems Engineering, Faculty of Agriculture, Shahid Chamran \\ University of Ahvaz, Ahvaz, Iran \\ ${ }^{2}$ Master of Agricultural Mechanization, Amir Kabir agro-Industry, Iran \\ *Corresponding author-mail: n.monjezi@scu.ac.ir \\ Received 19 August 2019; Accepted 18 November 2019; Available online 6 February 2021
}

\begin{abstract}
Canola production increased significantly in Iran due to its high yield in recent years. Khuzestan province is the main centre of canola production in Iran. This paper presents a data mining study of samples of canola obtained from farms in Amirkabir Agro-Industry of Khuzestan province. Data were collected from 48 farms. The farms were chosen by random sampling method. The purpose of this study is to determine energy consumption of input and output used in canola production. And Output energy of canola farms is predicted using data mining and multi-layer perceptron neural network. This is an analytic research and its database consists of 432 records. Data required for this research was obtained during growing seasons in 20172018. Data analysis was done by IBM SPSS modeler 14.2. The results showed that the amount of energy consumed in canola production was 28927.43 MJ ha- 1 . About $40 \%$ of this was generated by fertilizers and $37 \%$ from electricity and diesel fuel. Concerning the model used in the research, it was found that variables of chemical fertilizer, fuel, electricity energy and irrigation, respectively had the highest effect on output variable (productive energy). Amount of prediction precision in neural network algorithm meaning ratio of correctly predicted records to total records was $86.5 \%$. Also, linear correlation between actual values and predicted values was 0.84 and 0.88 respectively for training data and testing data suggesting strong correlation. Results obtained in this research can be effective for canola farmers in Amirkabir Agro-Industry in direction of evaluation and optimization of energy consumption in process of canola production and reduction of consumption of energy inputs.
\end{abstract}

Keywords: Energy, Predict, Data mining, Artificial Neural Networks (ANN), Canola.

\section{Introduction}

Timely predicting canola output energy is a very important task which we face currently. The relation between agriculture and energy is very close. Agricultural itself is an energy user and energy supplier in the form of bio-energy (Namdari, 2011). Until now, considerable studies have been conducted in different countries on energy use in agriculture (Yilmaz et al., 2005; Ozkan et al., 2011; Sefeedpari et al., 2014; Almaliki et al., 2016; Almaliki, 2017). Efficient use of energy resources is one of the major assets of eco-efficient and sustainable production, in agriculture (Taheri- 
Garavand et al., 2010). Therefore optimization and modeling of energy consumption are very important in production of agricultural products especially canola. On the other hand, collected data are various with complex relationship and it is difficult to analyze and manage them via empirical and statistical analyses and experiences. Data mining is a powerful technology in management and organization of a large size of information. Data mining means searching in one database for finding inter-data patterns. Several researches have been conducted on application of data mining techniques in agriculture. Medar \& Rajpurohit (2014) present the various crop yield prediction methods using data mining techniques. Different data mining techniques such as K-Means, K-Nearest Neighbor (KNN), Artificial Neural Networks (ANN) and Support Vector Machines (SVM) for very recent applications of data mining techniques in agriculture field. In addition, the references included in parentheses confirmed the ability and necessity of using data mining technique in agriculture (Raorane \& Kulkarni, 2013; Jeysenthil et al., 2014; Kalpana et al., 2014; Geetha, 2015; Raorane \& Kulkarni, 2015).

The main objectives of this study are to predict output energy of canola cultivation in Khuzestan province of Iran by means of data mining technique (Artificial Neural Networks).

\section{Materials \& Methods}

\section{Selection of case study region and data collection}

This study was conducted in Amirkabir AgroIndustry of Khuzestan province of Iran. The collected information belonged to the 20172018. Before collecting data, a pre-test survey was conducted by a group of randomly selected farms. The required sample size was determined using simple random sampling method. The equation is as below (Khoshnevisan et al., 2015):

$$
n=\frac{N \times s^{2} \times t^{2}}{(N-1) d^{2}+\left(s^{2} \times t^{2}\right)}
$$

In the formula, the below signs and letters represent:

$n$ is the required sample size, $N$ is the number of canola farms in target population, $s$ is the standard deviation in the pre-tested data, $t$ is the $t$ value at $95 \%$ confidence limit (1.96), and $d$ is the acceptable error. The permissible error in the sample size was defined to be $5 \%$ for $95 \%$ confidence. Thus the sample size was found to be 48 for collecting data appropriate questionnaire designed.

\section{Energy Equivalents of Inputs and Output}

In order to predict output energy, the data were converted into output and input energy levels using equivalent energy values for each commodity and input. Energy equivalents shown in table (1) were used for estimation.

Firstly, the amounts of inputs used in the production of canola were specified in order to calculate the energy equivalences in the study. Energy input includes human labor, diesel fuel, electricity, irrigation, machinery, fertilizers, chemical and seed amounts and output yield include canola. The units in Table 1 were used to find the input amounts. The amounts of input were calculated per hectare and then, these input data were multiplied with the coefficient of energy equivalent. The previous studies (cited in Table1) were used to determine the energy equivalents' coefficients. 
Monjezi \& Hosseinzadeh /Basrah J. Agric. Sci., 34(1): 28-37, 2021

Table (1): Energy equivalent of inputs and output in canola production.

\begin{tabular}{|c|c|c|c|}
\hline Item & Unit & Energy equivalent (MJ.kg-1) & Reference \\
\hline 1. Human labor & $\mathrm{h}$ & 1.96 & Taheri-Garavand et al., 2010 \\
\hline 2. Machinery & $\mathrm{Kg}$ & & \\
\hline a. Tractor & & 138 & Taheri-Garavand et al., 2010 \\
\hline b. Plow & & 180 & Taheri-Garavand et al., 2010 \\
\hline c. Disk harrow & & 149 & Salami et al., 2010 \\
\hline d. Planter & & 133 & Taheri-Garavand et al., 2010 \\
\hline $\begin{array}{l}\text { e. Equipment of } \\
\text { fertilizing }\end{array}$ & & 129 & Taheri-Garavand et al., 2010 \\
\hline f. Sprayer & & 129 & Taheri-Garavand et al., 2010 \\
\hline g. Combine & & 116 & Taheri-Garavand et al., 2010 \\
\hline h. Other machinery & & 62.7 & Mousavi-Avval et al, 2011 \\
\hline 3. Diesel fuel & Lit & 47.8 & Banaeian et al., 2011 \\
\hline 4. Chemicals & $\mathrm{Kg}$ & & \\
\hline a. Herbicide & & 238 & Erdal et al., 2007 \\
\hline b. Pesticide & & 101.2 & Erdal et al., 2007 \\
\hline c. Fungicide & & 216 & Erdal et al., 2007 \\
\hline 5. Fertilizers & $\mathrm{Kg}$ & & \\
\hline a. Nitrogen $(\mathrm{N})$ & & 78.1 & Pishgar Komleh et al., 2011 \\
\hline b. Phosphate $\left(\mathrm{P}_{2} \mathrm{O}_{5}\right)$ & & 17.4 & Pishgar Komleh et al., 2011 \\
\hline c. Potassium $\left(\mathrm{K}_{2} \mathrm{O}\right)$ & & 13.7 & Pishgar Komleh et al., 2011 \\
\hline 6. Water for irrigation & $m^{3}$ & 0.63 & Pishgar Komleh et al., 2011 \\
\hline 7. Electricity & $\mathrm{kWh}$ & 3.60 & Heidari \&_Omid, 2011 \\
\hline 8. Seed & $\mathrm{Kg}$ & 25 & Beheshti Tabar et al., 2010 \\
\hline
\end{tabular}

The energy equivalences of unit inputs are given in Mega Joule (MJ) unit .The total input equivalent can be calculated by adding up the energy equivalences of all inputs in MJ.

\section{Data mining technique}

The goal of data mining is to discover hidden knowledge in datasets which the human eye or conventional statistical analysis can-not uncover. There are a wide variety of techniques, called Predictive models, which are available to aid and perform predictive analysis (Maione, 2016). In this study, we used a popular technique which has yielded good results in the recent data mining literature: Artificial neural networks. A brief description of this technique follows.

\section{Artificial neural networks}

The simplest definition of an artificial neural network (ANN), is a simulation of biological neural system, it is a mathematical model or computational model based on biological neural networks (Arockiaraj, 2013). Neural networks are typically organized in layers. Layers are made up of number of interconnected 'nodes' which contain an activation function. Patterns are presented to the network via the 'input layer', which communicates to one or more 'hidden layers' where the actual processing is done via a system of weighted 'connections'. The hidden layers then link to an 'output layer'. Most ANNs contain some form of 'learning rule' which modifies the weights of the connections 
according to the input patterns that it is presented with. Therefore ANN is like human biological brain learns and recognize by examples and testing. The learning phase based on providing samples of real cases as inputs and use training methods to extract the relations between them to get another output from the given inputs, this is done by calculating the connective weights between layers that work as data processing on input to obtain better output. In learning phase large sample of dataset must cover most of the possible inputs that is considered as an expected rate of error which needs to be minimized as much as possible helping the proposed model to generalize on all possible data. Testing phase: based on providing a sample data considered as other inputs that ANN trained on and extract output to be compared with results to measure the system's ability to learn, and its reliability to predict and forecast the needed results to be adapted in the real life to be able to solve problems. A multilayer perceptron (MLP) is a feed forward artificial neural network model that maps sets of input data onto a set of appropriate output. It is a modification of the standard linear perceptron in that it uses three or more layers of neurons (nodes) with nonlinear activation functions, and is more powerful than the perceptron in that it can distinguish data that is not linearly separable, or separable by a hyperplane. Multilayer perceptron using a backpropagation algorithm are the standard algorithm for any supervised-learning pattern recognition process (Ayman et al., 2015).

\section{Data analysis}

Data mining software of IBM SPSS Modeler 14.2 has been used in the research for modeling neural network and result validation. Data were divided into training and testing data.
$70 \%$ of data were training and $30 \%$ of them were testing data.

\section{Model assessment}

In this stage, output model of training data was used for testing data. In other words, testing data (30\% of data in the research) are predicted by derived model and results of prediction are compared with reality using this model.

\section{Results \& Discussion}

\section{Analysis of energy input and output in canola production}

The input and output energy values used in canola production are illustrated in table (2). It is evident that, the total energy input for canola production was about $28927.43 \mathrm{MJ}$ ha $^{-1}$, from which, the highest share was consumed by fertilizers, followed by diesel fuel inputs and electrical energy. Several researchers reported that chemical fertilizers spatially nitrogen were the most energy consuming inputs followed by diesel energy (Ozkan et al., 2004; Mohammadi et al., 2008). On the other hand, the output energy was equal to $58638.75 \mathrm{MJ} \mathrm{ha}^{-1}$ in the farms that were studied. In the other columns of table (2) the standard deviation values, maximum values and minimum values for the inputs and output used in ANN model are presented.

\section{Data mining}

In present research, information collected from canola farms of Amirkabir Agro-industry was used as database. The stages of the second research phase are divided into six parts such as data identification and selection, data description, data pre-processing and preparation, data modeling and analysis, data evaluation and validation and model development. 
Monjezi \& Hosseinzadeh /Basrah J. Agric. Sci., 34(1): 28-37, 2021

Table (2). Amounts of energy inputs and output for canola production.

\begin{tabular}{lccccc}
\hline \multicolumn{1}{c}{ Item } & $\begin{array}{c}\text { Total energy } \\
\text { Equivalent } \\
\left(\mathbf{u n i t} \boldsymbol{h a}^{\mathbf{- 1}}\right)\end{array}$ & $\begin{array}{c}\text { Percentage } \\
(\boldsymbol{\%})\end{array}$ & $\begin{array}{c}\text { standard deviation } \\
(\mathbf{S D})\left(\mathbf{u n i t} \boldsymbol{h}^{\mathbf{- 1}}\right)\end{array}$ & $\begin{array}{c}\text { Max } \\
\left(\mathbf{u n i t} \boldsymbol{h} \boldsymbol{a}^{\mathbf{- 1}}\right)\end{array}$ & $\begin{array}{c}\text { Min } \\
\left(\mathbf{u n i t} \boldsymbol{h a}^{\mathbf{- 1}}\right)\end{array}$ \\
\hline Inputs & & & & & \\
\hline Human labor (MJ) & 183.05 & 0.63 & 35.71 & 238.18 & 120.22 \\
\hline Machinery (MJ) & 2398.49 & 8.29 & 170.55 & 2737.98 & 1940.06 \\
\hline Diesel fuel (MJ) & 5980.22 & 20.67 & 805.21 & 7543.29 & 4212.77 \\
\hline Chemicals (MJ) & 919.45 & 3.18 & 142.87 & 973.81 & 420.33 \\
\hline Fertilizers (MJ) & 11450.45 & 39.58 & 125.67 & 12980.30 & 9073.67 \\
\hline Electricity (MJ) & 4740.15 & 16.39 & 297.78 & 6065.79 & 4000.55 \\
\hline Irrigation (MJ) & 3025.62 & 10.45 & 205.61 & 2760.92 & 3500.73 \\
\hline Seed (MJ) & 230.00 & 0.79 & 5.04 & 237.50 & 200.00 \\
\hline Total energy input (MJ) & 28927.43 & 100 & 4311.92 & 17579.41 & 29422.83 \\
\hline Output & & & & \\
\hline canola yield (kg) & 2345.55 & - & 307.65 & 1990.50 & 2700 \\
\hline Total energy output (MJ) & 58638.75 & - & 1209.80 & 48886.51 & 65708.52 \\
\hline
\end{tabular}

\section{Stage of data identification and selection}

In the first stage, information available about consumed inputs in process of canola production has been studied. Concerning collected information, nine effective variables required for modeling energy consumption in process of canola production were defined and stored in informational bank of farms as separate fields. These eight variables are independent variables of the research and they are as follows: human labor, diesel fuel, electricity, irrigation, machinery, fertilizers, chemical and seed. Variable of output energy of the farm is dependent variable of the research.

\section{Data description and definition of Variables used in the model}

Data used in this research is entered in IBM SPSS modeler 14.2 in form of an Excel file with nine columns including eight independent variables (input) and one dependent variable (target).

\section{stage of data pre-processing and \\ Preparation}

Before modeling, raw data collected from canola farms were prepared and pre-processed for improvement of data quality. Data preprocessing and preparation include standardization of number of farms, standardization of unique values in different data sources, correction or deletion of inconsistent and irrational values and addition of different sources based on the number of standardized farm. Also, presence of unconventional records in database increased error factor in results of data mining. Therefore, identification and management of such unconventional data is very important in data preparation stage. Concerning statistical data description, there is no missing data among records in this stage.

\section{Stage of data analysis and modeling}

Data are modeled in this stage and necessary analyses are presented regarding model validation. In order to predict output energy of canola farms and to enter the software, final 
database had 432 records and 9 fields of input and output variables. In order to model data, field of output energy variable was introduced to the software as output and other variables (fields) were introduced to the software as input variables. The main algorithm used in this research for energy of canola farms is artificial neural network. The network used here is multilayer perceptron which is one of the most practical artificial neural networks. Number of hidden layers of the network is one layer with three neurons (Fig. 1). The condition for stopping modeling is that if error is not reduced, optimization will be stopped. In present model, data prediction precision was $86.5 \%$.

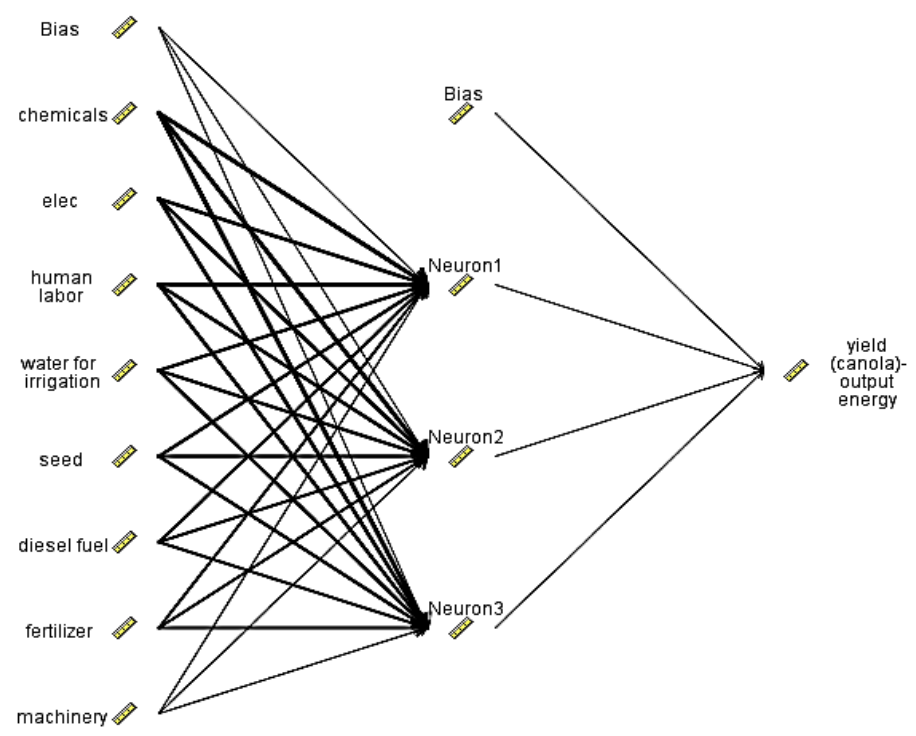

Fig. (1): Architecture of a multilayer perceptron.

Concerning description of input and output variables, it is noteworthy that some variables are more effective on prediction of model. In the graph of neural network in fig. (2), descending trend of effect of variables has been determined on target variable.

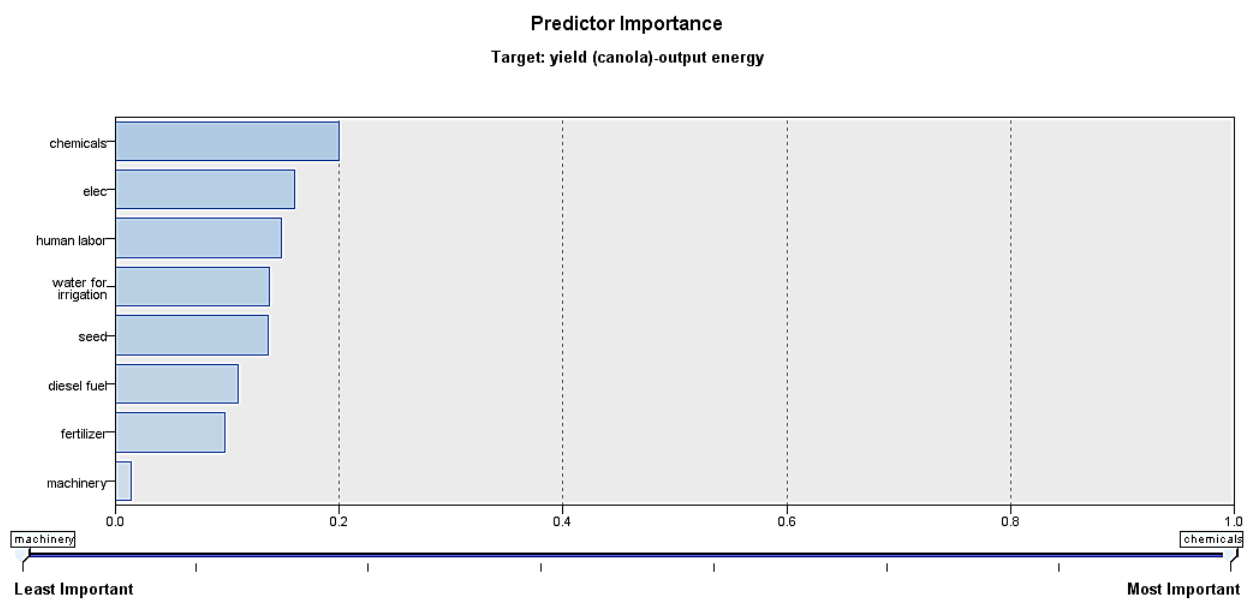

Fig. (2): Predictor importance (Target: output energy). 
The first variable with the highest effect is fertilizers. Fuel and electricity energy are other factors affecting output variable (productive energy). Other variables are effective as well but their effectiveness is less than the three variables.

\section{Model evaluation and validation}

After preparation of model, it should be evaluated. Evaluation results cause improvement of model and they make it practical. Since the method presented in every research should be measured based on validity and concerning that the research method is data-oriented, validation method is as follows: data are divided into two training and testing data collections. Training data makes the model and testing data evaluates the model. In other words, testing data were predicted by extracted model and prediction results are compared with reality by this model.

Data were divided randomly by software. Regarding number of data in each set, number of training data is always more than testing data. In present research, number of training sets is $70 \%$ (34 farms) and the rest (30\%) has been considered as testing data (14 farms). Validity value is tested by results of new data and training data are entered the algorithm as observer and evaluate results of its accuracy. Amount of prediction precision in neural network algorithm meaning the ratio of correct predicted records to total records was $86.5 \%$. Therefore, the model made by neural network has high estimative precision. Another argument is how precision of prediction methods can be measured. In order to evaluate precision of prediction models (the difference between the real value and predicted value of dependent variable), index of mean absolute value of prediction error is used. Mean absolute error value (MAE) of training data and testing data is 1531.20 and 2077.38 respectively which is an optimal value (Table 3 ). It is clear that in order to increase precision of a predictive method, the values of abovementioned indices should be small. Also, linear correlation between real and predicted values is 0.88 and $0.84 \%$ for training data and testing data respectively and it suggests a strong correlation.

\section{Model development}

In this stage, the model and its results can be presented to Amirkabir Agro-Industry manager to be used in future for prediction of energy production during the process of canola production. Therefore, after necessary reports; it was explained the most effective variables on prediction of output energy of canola farms based on this model. Concerning that variables of chemical fertilizers, fuel and electricity and

Table (3): Comparing predicted output energy with actual output energy.

\begin{tabular}{ccc}
\hline Partition & 1_Training & 2_Testing \\
\hline Minimum Error & -1713.71 & -239.03 \\
\hline Maximum Error & 1278.11 & 1617.44 \\
\hline Mean Error & -532.70 & -812.28 \\
\hline Mean Absolute Error & 1531.20 & 2077.38 \\
\hline Standard Deviation & 4990.18 & 5673.05 \\
\hline Linear Correlation & 0.88 & 0.84 \\
\hline Occurrences & 34 & 14
\end{tabular}


irrigation are the most effective variables on output energy of canola farms, energy efficiency will be increased in farms if input variables are optimized.

\section{Conclusion}

Data of canola farms was used in present paper. In the first research phase, input and output energies of canola farms were analyzed. Total energy consumption in canola production was $28927.43 \mathrm{MJ} \mathrm{ha}^{-1}$. The energy input of chemical fertilizer has the biggest share within the total energy inputs followed by fuel. Energy output was calculated as 58638.75 MJ.ha ${ }^{-1}$. In the second research phase (data mining), database was divided into training and testing parts. Then, a model was created based on artificial neural network technique of data mining in order to estimate energy in process of canola production using IBM modeler 14.2 and training dataset. As a result, the model was assessed using testing datasets and could reach $86.5 \%$ precision for estimation of output energy. It is clearly evident that this model has a good accuracy for estimation of amounts of output energy. Also, results of the study indicate that prediction methods provide proper source allocation and increase efficiency of inputs by presenting more accurate picture of energy status in canola farms.

\section{Acknowledgements}

This paper was supported by Shahid Chamran University of Ahvaz, Iran.

Conflict of interest: The authors declare that they have no conflict of interest.

\section{ORCID:}

\section{N. Monjezi: 0000000182297706}

\section{References}

Almaliki, S., Alimardani, R., \& Omid, M. (2016). Artificial neural network based modeling of tractor performance at different field conditions.
Agricultural Engineering International: CIGR Journal, $\quad 18, \quad 262-274$. https://cigrjournal.org/index.php/Ejounral/article/vi ew/3880

Almaliki, S. (2017). Development and evaluation of models for MF-285 tractor performance parameters using computational intelligence techniques. $\mathrm{Ph}$. D. Thesis. University of Tehran, 215pp.

Arockiaraj, M. (2013). Applications of Neural networks in data mining. International Journal of Engineering Science, $\quad 3, \quad 8-11$. https://scholar.google.com/citations?user=GBkItUAAAAJ\&hl=en\&oi=sra

Ayman, E.K.; Kadry, M. \& Walid, G. (2015). Proposed framework for implementing data mining techniques to enhance decisions in agriculture sector . Procedia Computer Science, 65, 633-642. https://doi.org/10.1016/j.procs.2015.09.007

Banaeian, N., Omid, M., \& Ahmadi, H. (2011). Energy and economic analysis of greenhouse strawberry production in Tehran province of Iran. Energy Conversion and Management, 52, 1020-1025. https://doi.org/10.1016/j.enconman.2010.08.030

Beheshti Tabar I.; Keyhani, A. \& Rafiee, S. (2010). Energy balance in Iran's agronomy (1990-2006). Renew. Renewable and Sustainable Energy Reviews, 14, 849-55. https://doi.org/10.1016/j.rser.2009.10.024

Erdal, G., Esengun, K., Erdal, H., \& Gunduz, O. (2007). Energy use and economic analysis of sugar beet production in Tokat province of Turkey. Energy, 32, 35-41. https://doi.org/10.1016/j.energy.2006.01.007

Geetha, M. C. S. (2015). A survey on data mining techniques in agriculture. International Journal of Computer and Communication Engineering, 3, 887892.

https://link.springer.com/article/10.1007/s12351009-0054-6

Heidari, M. D., \& Omid, M. (2011). Energy use patterns and econometric models of major greenhouse vegetable productions in Iran. Energy, 36, 220-225. https://doi.org/10.1016/j.energy.2010.10.048

Jeysenthil, K. M. S., Manikandan. T., \& Murali, E. (2014). Third generation agricultural support system development using data mining. International Journal of Innovative Science Engineering and Technology, 3, 9923-9930.

Kalpana, R., Shanthi, N., \& Arumugam, S. (2014). A Survey on data mining techniques in agriculture. International Journal of Advanced Computer Science and Information Technology, 3, 426-431. http://warse.org/pdfs/2014/ijacst05382014.pdf 


\section{Monjezi \& Hosseinzadeh /Basrah J. Agric. Sci., 34(1): 28-37, 2021}

Khoshnevisan, B., Rafiee, S., Iqbal, J., Shamshirband, Sh., Omid, M., Badrul Anuar, N., \& Abdul Wahab, A. W. (2015). A comparative study between artificial neural networks and adaptive neuro-fuzzy inference systems for modeling energy consumption in greenhouse tomato production: A case study. Isfahan Province. Journal of Agricultural Science and Technology, 17, 49-62. https://jast.modares.ac.ir/article-23-4013-en.html

Maione, C., Batista, B. L., Campiglia, A. D., Barbosa, F., \& Barbosa, R. M. (2016). Classification of geographic origin of rice by data mining and inductively coupled plasma mass spectrometry. Computers and Electronics in Agriculture, 121, 101107. https://doi.org/10.1016/j.compag.2015.11.009

Medar, R. A., \& Rajpurohit, V. S. (2014). A survey on data mining techniques for crop yield prediction. International Journal of Advance Research in Computer Science and Management Studies, 2, 5964. https://www.academia.edu/9421293

Mohammadi. A., Tabatabaeefar. A., Shahin. Sh., Rafiee. Sh., \& Keyhani. A. (2008). Energy use and economic analysis of potato production in Iran a case study: Ardabil province. Energy Conversion and Management, 49, 3566-3570.

https://doi.org/10.1016/j.enconman.2008.07.003

Mousavi-Avval, S. H., Rafiee, S., Jafari, A., \& Mohammadi, A. (2011). Improving energy use efficiency of canola production using data envelopment analysis (DEA) approach. Energy, 36, 2765-2772.

https://doi.org/10.1016/j.energy.2011.02.016

Namdari, M. (2011). Energy use and cost analysis of watermelon production under different farming technologies in Iran. International Journal of Environmental Science and Technology, 1, 11441153.

Ozkan, B.; Akcaoz. H. \& Karadeniz. F. (2004). Energy requirement and economic analysis of citrus production in Turkey. Energy Conversion and Management, 45, 1821-1830. http://iranarze.ir/wpcontent/uploads/2016/07/4701-English.pdf

Ozkan, B., Ceylan, R. F., \& Kizilay, H. (2011). Energy inputs and crop yield relationships in greenhouse winter crop tomato production. Renewable Energy, 36 ,

3217-3221.

https://doi.org/10.1016/j.renene.2011.03.042

Pishgar Komleh, S. H., Omid, M., \& Keyhani, A. (2011a). Study on energy use pattern and efficiency of corn silage in Iran by using Data Envelopment Analysis (DEA) technique. International Journal of Environmental Science and Technology, 1, 10941106.

Raorane, A. A., \& Kulkarni, R. V. (2013). Review- role of data mining in agriculture. International Journal of Computer Science and Information Technologies, 4 ,

270-272.

http://cloud.politala.ac.id/politala/1.\%20Jurusan/Te knik\%20Informatika/19.\%20e-

journal/Jurnal\%20Internasional\%20TI/IJCSIT/Vol \%204/ISSUE\%202/ijcsit20130402018.pdf

Raorane, A. A., \& Kulkarni, R. V. (2015). Application of data mining tool to crop management system. Russian Journal of Agricultural and SocioEconomic Sciences, 37, 3-16. https://ideas.repec.org/a/scn/031261/16082009.html

Salami, P., Ahmadi, H., \& Keyhani, A. R. (2010). Estimating the energy indices and profitability of strawberry production in Kamyaran zone of Iran. Energy Research Journal, 1, 32-35. https://doi.org/10.3844/erjsp.2010.32.35

Sefeedpari, P.; Shokoohi, Z., \& Behzadifar, Y. (2014). Energy use and carbon dioxide emission analysis in sugarcane farms: a survey on Haft-Tappeh Sugarcane agro industrial Company in Iran. Journal of Cleaner Production, 83, 212-219. https://doi.org/10.1016/j.jclepro.2014.07.048

Taheri-Garavand, A., Asakereh, A., \& Haghani, K. (2010). Energy elevation and economic analysis of canola production in Iran a case study: Mazandaran province. International Journal of Environmental Science, 1, 236-242.

Yilmaz, I., Akcaoz, H., \& Ozkan, B. (2005). An analysis of energy use and input costs for cotton production in Turkey. Renewable Energy, 30, 145-55. https://doi.org/10.1016/j.renene.2004.06.001 
تقييم استهلاك الطاقة لنظام إنتاج الكانولا في إيران (حالة الاراسة: منطقة امير كبير الصناعية الزراعية)

\author{
نسيم منجزي 1 و اسماعيل حسين زاده2

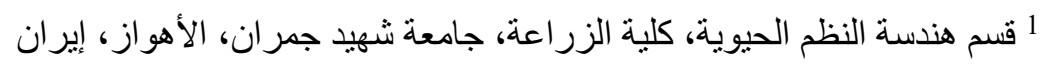

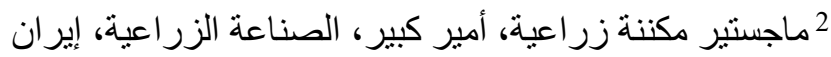

المستخلص: زاد إنتاج الكانو لا بشكل كبير في إيران بسبب ارتفاع إنتاجه في السنوات الأخيرة. تعد محافظة خوزستان هي المركز

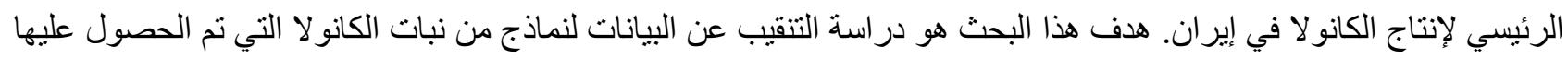

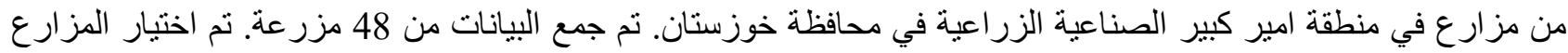

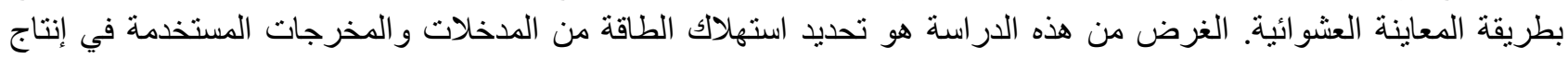
الكانو لا. ويتم توقع الطاقة الناتجة من مز ارع الكانو لا باستخدام التتقيب عن البيانات و الثنبكة العصبية متعددة الطبقات. ويعد بحث

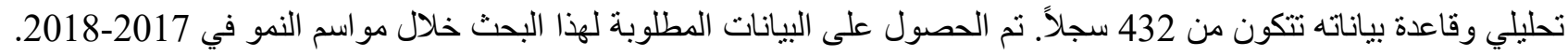

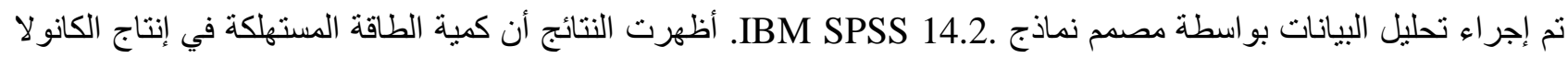

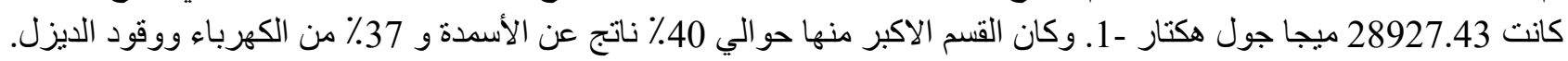

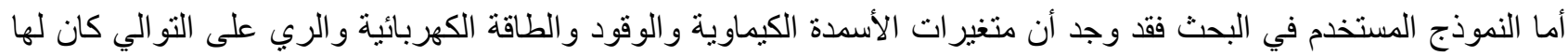

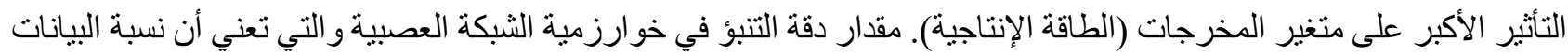

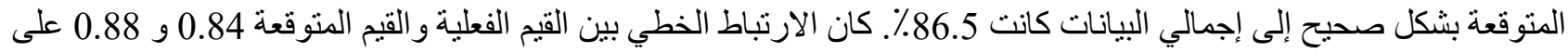

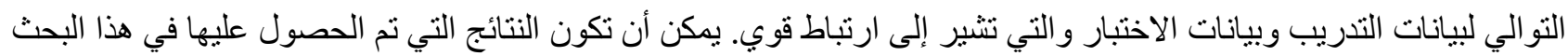

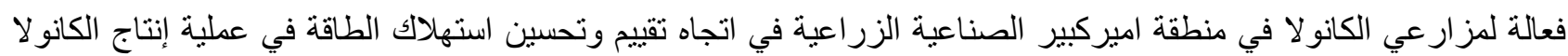

وتقليل استهلاك مدخلات الطاقة. الكلمات المفتاحية: الطاقة ، التتبؤ ، التنقيب في البيانات ، الثبكات العصبية الاصطناعية (ANN) ، الكانو لا . 